\title{
Synovial Lipomatosis; A Clinicopathological Study of a Rare Entity
}

\author{
Shaarif Bashir ${ }^{1}$, Usman Hassan ${ }^{2}$, Noreen Akhtar ${ }^{3}$, Sajid Mushtaq ${ }^{4}$ \\ Department of Pathology, Shaukat Khanum Memorial Cancer Hospital and Research Centre, Lahore, Pakistan
}

\section{ABSTRACT}

Objective: This study was conducted to analyse the clinicopathological and radiological features associated with Synovial lipomatosis.

Patients and Methods: Cases diagnosed as Synovial lipomatosis from 2008 to 2018 were retrieved and clinical information and histology were reviewed.

Results: Thirteen cases of Synovial lipomatosis were diagnosed between 2008 and 2018. Most common site was knee joint and mean age of presentation was 28.6 . About $62 \%$ of subjects were males and mostly presented with joint pain and swelling. Two of the subjects had significant history of trauma and disease was bilateral in one of the cases. Microscopically, villous proliferation of synovium with infiltration of mature adipocytes was noted. Focal synovial hyperplasia and inflammatory infiltrate were other findings in some of the cases.

Conclusion: Synovial lipomatosis should be considered in the differential diagnosis of joint pain and swelling and should be distinguished from Pigmented villonodular synovitis, Synovial haemangioma and intra-articular synovial lipoma (IASL) using radiological and histological features.

Key words: Synovial hyperplasia, Synovial haemangioma, Synovial lipomatosis

Author's Contribution

${ }^{1}$ Conception, synthesis, planning of research

and manuscript writing Interpretation and

discussion

${ }^{2-4}$ Data analysis, interpretation and

manuscript writing, Active participation in

data collection.

Cite this article. Bashir S, Hassan U, Akhtar N, Mushtaq S. Synovial Lipomatosis, A

Clinicopathological study of a rare entity. JIMDC.2018; 7(4):235-238

\section{Address of Correspondence Article info.}

Usman Hassanjj

Received: September 13, 2018

Accepted: November 10, 2018

Email:drusmanhassan256@gmail.com

\section{Introduction}

Synovial Lipomatosis, also known as Lipoma Arborescens, is a rare pseudotumor, which arises from the synovial lining of the joints. It usually involves the knee joint, particularly the supra-patellar pouch, but can affect any joint in the body, even the tendon sheath and bursa, which have the synovial lining. ${ }^{1}$ The exact etiology is still unclear. Peak incidence is between fifty and seventy years and there is a slight predilection for males. ${ }^{2}$ Patients present with joint pain, swelling and effusion. Synovial lipomatosis can be bilateral in some cases. ${ }^{3}$

Radiologically, synovial lipomatosis presents as a frondlike mass along with joint effusion arising from the synovium with subcutaneous fat-equivalent signal on all pulse sequences of MRI. ${ }^{3}$ Histologically, there is synovial hyperplasia with synovial membrane lined villous structures infiltrated by mature adipocytes. Mild chronic inflammation is present as well. ${ }^{4}$ Treatment options include open and arthroscopic synovectomy. ${ }^{5-9}$

As it is a rare entity with less than 100 cases reported so far, the clinical, radiological and pathological data available is very limited and varied. ${ }^{3}$ The purpose of our study is to contribute to the literature the clinical details (age, gender, clinical presentation), radiological and 


\begin{tabular}{|c|c|c|c|c|c|c|c|c|}
\hline \multicolumn{9}{|c|}{ Table 1: Bio data and significant clinical details } \\
\hline $\begin{array}{c}\text { Serial } \\
\text { No }\end{array}$ & Age & Gender & Site & Laterality & Duration & $\begin{array}{c}\text { Size } \\
(\mathbf{m m})\end{array}$ & $\begin{array}{c}\text { Significant } \\
\text { History }\end{array}$ & Clinical Presentation \\
\hline $\mathbf{1 .}$ & 19 & Male & Knee & Bilateral & 2 years & 42 & $\begin{array}{c}\text { Fever (on and } \\
\text { off) }\end{array}$ & Pain and swelling \\
\hline $\mathbf{2 .}$ & 60 & Female & Wrist & Left & Not known & 30 & Not known & Ganglion on wrist \\
\hline $\mathbf{3 .}$ & 26 & Female & Knee & Left & 18 years & 35 & Not known & Swelling \\
\hline $\mathbf{4 .}$ & 20 & Male & Ankle & Right & Not known & 20 & Not known & Not known \\
\hline $\mathbf{5 .}$ & 60 & Male & Knee & Right & Not known & 85 & Not known & Pain and swelling \\
\hline $\mathbf{6 .}$ & 40 & Male & Knee & Right & Not known & - & Not known & Swelling \\
\hline $\mathbf{7}$ & 15 & Female & $\begin{array}{c}\text { Dorsum } \\
\text { of hand }\end{array}$ & Not known & Not known & 18 & Not known & Swelling \\
\hline $\mathbf{8 .}$ & 30 & Male & Knee & Left & 6 months & 3 & $\begin{array}{c}\text { Trauma 3 } \\
\text { years ago }\end{array}$ & Pain \\
\hline $\mathbf{9 .}$ & 16 & Male & Knee & Left & Not known & 55 & Not known & Pain and swelling \\
\hline $\mathbf{1 0 .}$ & 10 & Female & Knee & Right & 4 years & 65 & $\begin{array}{c}\text { Trauma 4 } \\
\text { Pears ago }\end{array}$ & $\begin{array}{c}\text { Pain, Swelling and } \\
\text { restricted mobility }\end{array}$ \\
\hline $\mathbf{1 1 .}$ & 40 & Female & Knee & Right & Not known & 11 & Not known & Pain \\
\hline $\mathbf{1 2 .}$ & 15 & Male & Knee & Right & Not known & 35 & Not known & Not known \\
\hline $\mathbf{1 3 .}$ & 21 & Male & Knee & Left & 9 years & 143 & Not known & Pain and Swelling \\
\hline
\end{tabular}

histological features of the cases reported at our centre in the last decade and provide a better understanding of this condition to physicians, radiologists and pathologists.

\section{Patients and Methods}

The cases of Synovial Lipomatosis, diagnosed on histological examination, between 2008 and 2018 at Shaukat Khanum Cancer Hospital and Research Centre were retrieved. All the relevant information e.g. age, gender, site, size, significant history and clinical findings were analysed. Case slides were reviewed and pertinent histological findings were re-confirmed and additional findings like vascular proliferation, fibrosis and inflammation were looked for. All the biopsy proven cases of Synovial Lipomatosis were included in the study. Cases like Intra-Articular Synovial lipoma, pigmented villonodular synovitis and Synovial heamangioma which may mimic synovial lipomatosis but do not fulfil the histological criteria were excluded from the study.

\section{Results}

Thirteen cases of Synovial Lipomatosis were diagnosed at our centre in the last decade from 2008 to 2018 (Table
1). The age of presentation ranged from 10 years to 60 years with mean age of presentation 28.6 years. Eight of the thirteen patients $(61.5 \%)$ were males. Knee joint was the site of involvement in $10(76.9 \%)$ cases and wrist joint, ankle and dorsum of hand in the other three cases respectively. Bilateral joint involvement was observed in only one case $(7.7 \%)$. Two of the thirteen patients $(15.4 \%)$ had a history of trauma. Presenting complaint of nine patients (69.2\%) was swelling of the joint and seven $(53.9 \%)$ amongst them felt pain as well. Two cases (15.4\%) had restriction of movement of joint, as a result of swelling and the pain. The size of the lesion ranged from $3 \mathrm{~mm}$ to $143 \mathrm{~mm}$ with mean size of $45 \mathrm{~mm}$. Microscopic examination of the cases revealed villous proliferation of hyperplastic synovium with infiltration of mature adipocytes.

\section{Discussion}

Synovial Lipomatosis, also called as Lipoma Arborescens and Hoffa disease, is a rare tumor-like condition of synovial lining of the joints characterized by villous proliferation of synovium with infiltration of mature adipose tissue. It was first described by Albert Hoffa in 1904, as a 
condition involving the infrapatellar fat pad of athletes, and later in more detail by Arzimanoglu in 1957. 1,3,7 Less than 100 cases have been reported so far mostly as case reports. ${ }^{2}$ The exact etiology is unclear but association with trauma resulting in a reactionary inflammation and synovial hyperplasia has been proposed. ${ }^{1,3}$ Moreover, association with inflammatory joint diseases like osteoarthritis, rheumatoid arthritis, psoriasis and uveitis has been reported in the literature. ${ }^{3,4} \mathrm{~A}$ peculiar association with short bowel syndrome was reported by Siva et al in a case with multiple joints involvement of a patient with short bowel syndrome, suggesting that it results from abnormal deposition of fat in joints as a result of reduced fat absorption in resected small bowel. ${ }^{10}$ In our study, only two subjects had a history of trauma and that too more than 5 years ago.

Synovial Lipomatosis occurs commonly between 50 to 70 years with mean age of 45.6 years and a predilection for male gender. ${ }^{1}$ In a study by Rao $S$ et al. of 8 cases, subjects ranged from 1 to 73 years with mean age $45.2 .^{1}$ In our study, the mean age of presentation was 28.6 years and subjects ranged from 10 to 60 years. In both the studies, more than $60 \%$ of the patients were males. Although, the lesion usually involves the knee joint but it can present in any joint of body, even the tendons and bursae as they are also lined by synovium. ${ }^{1}$ Involvement of hip, elbow, wrist and shoulder joints has been noted as well. Bilateral/multiple joint involvement is uncommon. Knee joint was commonest site of involvement in our subjects $(76.9 \%)$ and the rest had diseases of ankle, wrist joint and dorsum of hand. One patient had bilateral knee joint involvement as well. Clinically, patient presents with pain and swelling of joint with limited mobility. Joint effusion and crepitus are also noted sometimes. ${ }^{1,3}$ Effusion causes pressure effect leading to the swelling and pain in the joint. The sign and symptoms in our study were almost the same as those reported in literature. Swelling of the joint(s) was the most common presentation followed by pain and limited mobility of joint. The diagnosis of Synovial Lipomatosis requires a combination of radiology and histopathogical examination. Magnetic Resonance Imaging (MRI) remains the gold standard modality and shows an intra-articular frond-like synovial mass with fat equivalent high signal intensity (Both T1 and T2) which is suppressed using fat suppressed sequences.,6,11 Other findings include joint effusion, bone erosions, synovial cyst and degenerative changes. Arthroscopy of joint also reveals villous proliferation of the synovium. On gross examination, the lesion of Synovial Lipomatosis is pale yellow, soft to firm with villous architecture. Microscopic examination is essential for definite diagnosis. Histologically, there is villous proliferation of synovium with infiltration of mature adipocytes (Fig 1a and 1b). ${ }^{1-3}$ Synovial hyperplasia, mild inflammation, dilated blood vessels and fibrosis can be present.3,9 The differential diagnoses of Synovial Lipomatosis include Synovial lipoma, Pigmented villonodular synovitis, Synovial haemangioma and intraarticular synovial lipoma (IASL). The later presents as a solitary nodular lesion in contrast to multiple villous projections in Synovial lipomatosis.

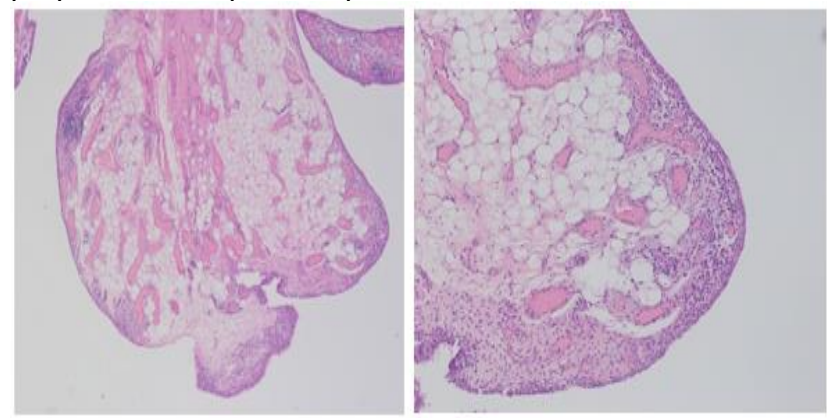

Figure 1: Biopsy from knee joint. (a) Villous structure lined by synovial membrane infiltrated by mature adipocytes. (Hematoxylin and Eosin, 20x). (b) Adipocytes and congested vessels in sub epithelial tissue. (Hematoxylin and Eosin, 20x)

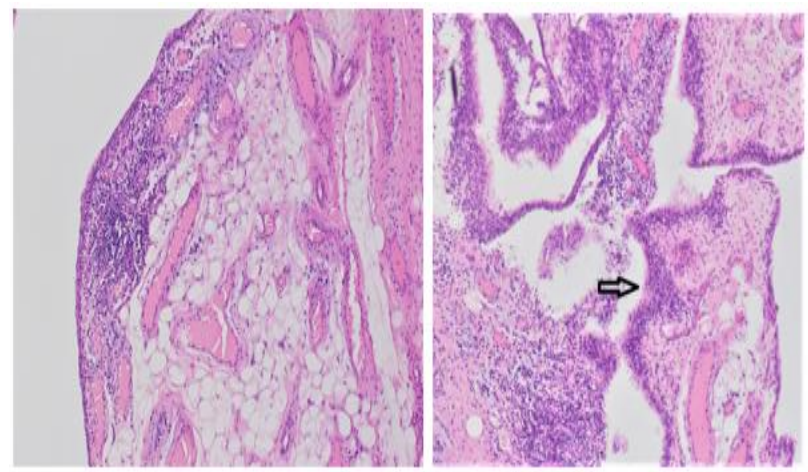

Figure 2 (a) Synovial tissue with infiltration of mononuclear inflammatory infiltrate and mature adipocytes. (Hematoxylin and Eosin 20x) (b) Synovial lining of villi showing focal hyperplasia (arrow). (Hematoxylin and Eosin, 20x) 
Histologically, IASL is composed of manure adipose cells covered by thin fibrous layer. Unlike Synovial lipomatosis, villous proliferation of synovium is absent in Intra-articular synovial lipoma. ${ }^{1,3,9}$

Pigmented villonodular synovitis (PVNS) is characterized by papillary projections of hyperplastic synovium composed of foamy cells and hemosiderin-laden macrophages. There are large pseudoglandular spaces lined by synovial cells, epithelioid cells and multinucleated giant cells. Absence of hemosiderin laden macrophages is a major differentiating feature of Synovial lipomatosis from PVNS.1,3 Synovial hemangioma shows synovium with dilated and congested vascular spaces. Lack of fat infiltration, villous architecture and synovial hyperplasia separates it from Synovial lipomatosis. ${ }^{3}$ The treatment of choice for Synovial lipomatosis is arthroscopic synovectomy especially when the disease is limited to one compartment. Larger lesion, however, requires open synovectomy. Recurrence is uncommon after synovectomy. $1,5,8,9$

\section{Conclusion}

Synovial lipomatosis is a rare psuedotumor, of unknown etiology, arising from synovial lining of joints characterized by villous proliferation of synovium with infiltration of adipocytes. Clinical presentation can vary but MRI and histopathological findings are characteristic and help in definite diagnosis. Treatment by arthroscopic or open synovectomy is enough with very low rates of recurrence.

\section{References}

1. Rao S, Rajkumar A, Elizabeth MJ, Ganesan V, Kuruvilla S. Pathology of synovial lipomatosis and its clinical signifcance. J Lab Physicians 2011;3(2):84-8.
2. Das S, Chattopadhyay P, Ray A, Sharma V. Incidental diagnosis of bilateral synovial lipomatosis in long standing knee osteoarthritis. Human Pathology: Case Reports 2015; 2(4): 103-105

3. Vleeschhouwer MD, Steen EVD, Vanderstraeten G, Huysse W, Neve JD, Bossche LV. Lipoma Arborescens: Review of an Uncommon Cause for Swelling of the Knee. Case Reports in Orthopedics 2016.2016, Article ID 9538075, 5 pages.

4. Natera, L, Gelber, P.E, Erquicia, J.I. et al. J Orthopaed Traumatol (2015) 16: 47.

5. Beyth S, Safran O. Synovial Lipomatosis of the Glenohumeral Joint. Case Reports in Orthopedics 2016; Article ID 4170923.

6. Miladore N, Childs MA, Sabesan VJ. Synovial lipomatosis: A rare cause of knee pain in an adolescent female. World J Orthop. 2015;6(3):369-73

7. Hoffa. The influence of the adipose tissue with regard to the pathology of the knee joint. The Journal of the American Medical Association 1904; 43(12): 795-796

8. Ji J-H, Lee Y-S, Shafi M. Spontaneous recurrent hemarthrosis of the knee joint in elderly patients with osteoarthritis: an infrequent presentation of synovial lipoma arborescens, Knee Surgery, Sports Traumatology, Arthroscopy 2010; 18(10):13521355

9. Kamran F, Kavin K, Vijay S, Shivanand G (2015) Bilateral lipoma arborescens with osteoarthritis knee: Case report and literature review. J Clin Orthop Trauma. 2015; 6(2):131-136

10. Siva C, Brasinton R, Totty W, Sotelo A, Atkinson J. Syonovial lipomatosis (lipoma arborescens) affecting multiple joints in a patient with congenital short bowel syndrome. J Rheumatol 2002;29(5):1088-92.

11. Babar SA, Sandison A, Mitchell AW. Synovial and tenosynovial lipoma arborescens of the ankle in an adult: A case report. Skeletal Radiol 2008; 37(1):757 